\title{
Comparison of Different Methods for RNA Extraction from Floral Buds of Tree Peony (Paeonia suffruticosa Andr.)
}

\author{
Yan GAO, Guangqi ZHAO, Changhua JIANG, \\ Yao SONG, Kang YE, Shucheng FENG*
}

\author{
Shanghai Botanical Garden, No. 1111 Longwu Road, 200231 Shanghai, \\ China; shbg2009@126.com (*orresponding author)
}

\begin{abstract}
Tree peony (Paeonia suffruticosa Andr.), a species native to China, is one of the most important ornamental and medicinal plants. Like other tree species in temperate and boreal zones, the dormancy-activity transition of floral buds is critical for blooming time and fruit production. However, floral buds contain high levels of secondary metabolites, making the isolation of high quality RNA difficult. To obtain a method suitable for extracting RNA from floral buds of tree peony, we evaluated five different methods, including the cetyltrimethylammonium bromide (CTAB) and Sodium dodecyl sulfate (SDS)-based methods, a modified SDS-TRNzol protocol, and two commercial kits (TRNzol and Qiagen RNeasy Plant Mini Kit). The modified SDS-TRNzol method was capable of efficiently removing polyphenols and other metabolites in floral buds. The isolated RNA was of high purity and integrity, as demonstrated by the the $\mathrm{A}_{260 / 280}$ ratio of approximately 2.0, and RIN values of more than 9.0. Gel electrophoresis analysis indicated that the extracted RNA had clear 28S and 18S ribosomal RNA bands without DNA contamination. The RNA isolated by this protocol was successfully used for downstream manipulations, such as RT-PCR, RACE, and real-time PCR. Together, the modified SDS-TRNzol protocol is an easy, efficient, and highly reproducible method for RNA isolation from floral buds rich in secondary metabolites.
\end{abstract}

Keywords: expression analysis; RNA isolation; secondary metabolites

\section{Introduction}

The floral industry has comprised an important part of the global economy, featured as cultural and high-added values. Tree peony (Paeonia suffruticosa Andr.) is a species native to China, being one of the most important ornamental and medicinal plants worldwide (Wister, 1995). Like other tree species native to temperate and boreal zones, the dormancy-activity transition of floral buds is important for blooming time and fruit production (Cooke et al., 2012). The dormancy of floral buds is a major bottleneck for the seasonal flowering of tree peony. Technically, the dormant buds can be effectively induced to bloom by chilling treatment (Horvath, 2009). However, the mechanism underlying the dormancy-activity transition of floral buds by chilling treatment is largely unknown. Thus, it is attractive and important to investigate the developmental profiles of floral buds at molecular level.

The extraction of high quality RNA is a prerequisite step for biological research at transcriptional level. However, floral buds often contain high levels of carbohydrates, anthocyanidin, polyphenols, hormones, and other secondary metabolites (Mornya et al., 2011; Li et al., 2012). These rigid and complicated compounds make the isolation of high quality RNA from floral buds extremely difficult. So far, a bunch of different RNA extraction protocols have been developed to isolate intact RNA from samples with abundant polysaccharides, polyphenols and secondary metabolites. To obtain a method suitable for extracting high quality RNA from secondary metabolites-rich floral buds of tree peony, we evaluated five different methods, including the cetyltrimethylammonium bromide (CTAB) (Chang et al., 1993) and Sodium dodecyl sulfate (SDS)-based methods (Zhou et al., 1999; Wu et al., 2006), a modified SDS-TRNzol protocol (Wang et al., 2012), and two commercial kits (TRNzol and Qiagen RNeasy Plant Mini Kit). Here, we present an effective and rapid protocol based on the combination of SDS and TRNzol, allowing isolating high quality total RNA from floral buds of tree peony.

\section{Materials and Methods}

Plant material

Tree Peony (Paeonia suffruticosa Andr.) cultivar 'Fengdan' 
plants were cultivated in the field in Shanghai Botanical Garden, Shanghai, China. Floral buds undergoing the dormancy-activity transition were collected at the end of November. After cutting, the buds were harvested and frozen in liquid nitrogen, and stored at $-80^{\circ} \mathrm{C}$ for RNA isolation.

\section{Reagents andsolutions}

All reagents used in this study were of analytic purity. Plastic materials (tubes and pipette tips) were pretreated overnight in $0.1 \%$ diethyl pyrocarbonate (DEPC) water and then autoclaved. The mortar, pestle and ironware were baked for 3-6 h at $180{ }^{\circ} \mathrm{C}$. RNeasy Plant Mini Kit (Qiagen, Germany), TRNzol (TIANGEN, Beijing, China), Phenol solution (Sigma, P4682, Saturated with 0.1 M citrate buffer, $\mathrm{pH} 4.3 \pm 0.2$ ). The following buffers and solutions were prepared:

- CTAB extraction buffer: 2\% (w/v) CTAB, $100 \mathrm{mM}$ Tris-HCl (pH8.0), 25 mM EDTA (pH8.0), 2\% (w/v) polyvinyl pyrrolidone (PVP), $2 \mathrm{M} \mathrm{NaCl}$, add $1 \%(\mathrm{v} / \mathrm{v}) \beta$ mercaptoethanol before use.

- SSTE washing buffer: $10 \mathrm{mM}$ Tris- $\mathrm{HCl}$ (pH8.0), 1 mMEDTA ( $\mathrm{pH} 8.0), 0.5 \%(\mathrm{w} / \mathrm{v})$ SDS, $1 \mathrm{M} \mathrm{NaCl}$.

- SDS extraction buffer: 100 mM Tris- $\mathrm{HCl}$ ( $\mathrm{pH}$ 9.0), add $2 \% \beta$-mercaptoethanol (v/v) before use.

- $20 \%$ SDS (Sodium dodecyl sulfate) (w/v), add $0.1 \%$ DEPC, autoclave and store at room temperature.

\section{Protocols}

The following protocols were used:

- CTAB method (adapted from Chang et al., 1993 with modifications)

(1) Floral buds were ground into fine power in liquid nitrogen by using mortar and pestle.

(2) A volume of $6 \mathrm{~mL}$ CTAB extraction buffer was added to the powder $(1 \mathrm{~g})$ in an RNase-free $15 \mathrm{~mL}$ tube; the sample was mixed thoroughly using a vortexer and incubated at $65^{\circ} \mathrm{C}$ for $15 \mathrm{~min}$ with occasional inversion.

(3) An equal volume of chloroform: isoamyl alcohol (24:1, $\mathrm{v} / \mathrm{v}$ ) was added and mixed thoroughly; the mixture was centrifuged at $12,000 \mathrm{rpm}$ for $10 \mathrm{~min}$ at room temperature.

(4) The supernatant was transferred to a new $15 \mathrm{~mL}$ tube and then repeated step (3).

(5) The aqueous phase was carefully transferred to a fresh tube, $1 / 3$ volume of $8 \mathrm{M} \mathrm{LiCl}(2 \mathrm{~mL})$ was added, mixed gently by inversion and incubated at $4^{\circ} \mathrm{C}$ for $8 \mathrm{~h}$.

(6) After centrifugation at $12,000 \mathrm{rpm}$ for $20 \mathrm{~min}$ at $4{ }^{\circ} \mathrm{C}$, the supernatant was discarded and the pellet was resuspended in $0.5 \mathrm{mLSSTE}$ buffer.

(7) The sample were transferred into a new $1.5 \mathrm{~mL}$ tube, an equal volume of phenol: chloroform: isoamyl alcohol (25: 24:1) was added and mixed thoroughly.

(8) The mixture was centrifuged at 12.000 rpm for $10 \mathrm{~min}$ at $4^{\circ} \mathrm{C}$, the supernatant was collected in a new $1.5 \mathrm{~mL}$ tube and an equal volume of chloroform: isoamyl alcohol (24:1) was added and mixed thoroughly.

(9) After centrifugation at $12,000 \mathrm{rpm}$ for $10 \mathrm{~min}$ at $4{ }^{\circ} \mathrm{C}$, the supernatant was transferred into a fresh $1.5 \mathrm{~mL}$ tube, $1 / 10$ volume of $3 \mathrm{M}$ sodium acetate ( $\mathrm{pH} 4.8$ ) and 2 volume of ice-cooled ethanol was added and mixed by inversion several times, and precipitated at $-80^{\circ} \mathrm{C}$ for $30 \mathrm{~min}$.
(10) After centrifugation at $12,000 \mathrm{rpm}$ for $20 \mathrm{~min}$ at $4{ }^{\circ} \mathrm{C}$, the supernatant was removed using a pipette and $500 \mu \mathrm{L}$ of pre-cooled $70 \%$ ethanol was added.

(11) The sample was centrifuged at 12,000 rpm for $5 \mathrm{~min}$ at 4 ${ }^{\circ} \mathrm{C}$, the supernatant was discarded and the pellet was allowed to dry at room temperature for $10 \mathrm{~min}$.

(12) An appropriate volume of DEPC-treated $\mathrm{H}_{2} \mathrm{O}$ was used to dissolve the pellet, and then stored at $-80^{\circ} \mathrm{C}$ for further use.

- SDS method (according to Zhou et al., 1999; Wu et al., 2006)

(1) The powder $(1 \mathrm{~g})$ was suspended into $6 \mathrm{~mL}$ SDS extraction buffer, mixed thoroughly using a vortexer and incubated at room temperature for $15 \mathrm{~min}$ with occasional inversion.

(2) A volume of $300 \mu \mathrm{L} 20 \%$ SDS was added into the mixture, and inverted gently for 5-8 times and incubated at room temperature for $5 \mathrm{~min}$.

(3) After centrifugation at $12,000 \mathrm{rpm}$ for $10 \mathrm{~min}$ at $4{ }^{\circ} \mathrm{C}$, the supernatant was transferred into a new tube and $1 / 3$ volume of $8 \mathrm{M} \mathrm{LiCl}(2 \mathrm{~mL})$ was added, mixed gently by inversion and incubated at $4^{\circ} \mathrm{C}$ for $8 \mathrm{~h}$.

(4) The following steps are the same as the CTAB method step 6-12.

- SDS-TRNzol method (adapted from Wang et al., 2012)

(1) Approximately $0.2 \mathrm{~g}$ powder was suspended into $0.4 \mathrm{~mL}$ SDS extraction buffer, mixed thoroughly and incubated at room temperature for $15 \mathrm{~min}$ with occasional inversion.

(2) A volume of $20 \mu \mathrm{L} 20 \%$ SDS was added into the suspension inverted gently for 5-8 times and incubated at room temperature for $5 \mathrm{~min}$.

(3) After centrifugation at $12,000 \mathrm{rpm}$ for $10 \mathrm{~min}$ at $4{ }^{\circ} \mathrm{C}$, the supernatant was transferred into a new tube and 2 volume of TRNzol $(0.8 \mathrm{~mL})$ was added, mixed thoroughly and incubated at room temperature for 10 $\min$.

(4) $1 / 5$ volume of chloroform $(240 \mu \mathrm{L})$ was added and mixed thoroughly, then centrifuged at $12,000 \mathrm{rpm}$ for 10 $\min$ at $4^{\circ} \mathrm{C}$

(5) The supernatant $(0.7 \mathrm{~mL})$ was carefully transferred to a fresh tube, an equal volume of isopropanol was added, and mixed by inversion several times, and precipitated at $20^{\circ} \mathrm{C}$ for $20 \mathrm{~min}$.

(6) The following steps are the same as the CTAB method step 6-12.

- TRNzolmethod (TIANGEN, Beijing, China)

(1) Approximately $0.4 \mathrm{~g}$ powder was suspended into $1 \mathrm{~mL}$ TRNzol, mixed thoroughly and incubated at room temperature for $10 \mathrm{~min}$.

(2) $1 / 5$ volume of chloroform $(200 \mu \mathrm{L})$ was added and mixed thoroughly, then centrifuged at 12,000 rpm for 10 $\min$ at $4^{\circ} \mathrm{C}$.

(3) The supernatant $(0.5 \mathrm{~mL})$ was carefully transferred to a fresh tube, an equal volume of isopropanol was added, and mixed by inversion several times, and precipitated at room temperature for $10 \mathrm{~min}$.

(4) The following steps are the same as the CTAB method step 10-12.

- RNeasy Plant Mini Kit (Qiagen, Germany)

(1) Approximately $0.1 \mathrm{~g}$ powder was suspended into $450 \mu \mathrm{l}$ 
420

Buffer RLT or Buffer RLC $1 \mathrm{~mL}$ TRNzol, mixed thoroughly and transferred the lysate to a QIAshredder spin column placed in a $2 \mathrm{ml}$ collection tube, and centrifuged for $2 \mathrm{~min}$ at full speed.

(2) The supernatant of the flow-through was carefully transferred to a new microcentrifuge tube, $1 / 2$ volume of ethanol (96-100\%) was added to the cleared lysate, and mix immediately by pipetting, and the mixture was transferred to an RNeasy spin column placed in a $2 \mathrm{ml}$ collection tube, and centrifuged for $15 \mathrm{~s}$ at $\geq 8000 \mathrm{~g}$ (or $\geq 10,000 \mathrm{rpm}$ ).

(3) A volume of $700 \mu \mathrm{l}$ Buffer RW1 was added to the RNeasy spin column, and centrifuged for $15 \mathrm{~s}$ at $\geq 8000 \mathrm{~g}$ $(\geq 10,000 \mathrm{rpm})$ to wash the spin column membrane.

(4) An volume of $500 \mu \mathrm{l}$ Buffer RPE was added to the RNeasy spin column, and centrifuged for $15 \mathrm{~s}$ at $\geq 8000 \mathrm{~g}$ $(\geq 10,000 \mathrm{rpm})$ to wash the spin column membrane, then repeated this step.

(5) The RNeasy spin column was placed in a new $1.5 \mathrm{ml}$ collection tube, and an appropriate volume of DEPCtreated $\mathrm{H}_{2} \mathrm{O}$ was used to dissolve the pellet, and then stored at $-80{ }^{\circ} \mathrm{C}$ for further use.

\section{Evaluation of RNA quantity and quality}

The quantity and purity of the isolated total RNA was determined through the ratios of $\mathrm{A}_{260 / 280}$ and $\mathrm{A}_{260 / 230}$, using the NanoDrop $^{\text {TM }} 1000$ spectrophotometer (Thermo Scientific). RNA integrity was evaluated by electrophoresis on a $1.0 \%$ native agarose gel at $5 \mathrm{~V} / \mathrm{cm}$, with $\mathrm{EtBr}$ (Ethidium Bromide) staining. RIN (RNA integrity number) values were calculated using the Eukaryote Total RNA Nano assay on an Agilent 2100 Bioanalyzer with RNA 6000 Nano LabChip (Agilent Technologies, CA, USA).

\section{Reverse transcription and downstream applications}

The remnant amount of DNA contamination was removed by using RNase-free DNase I (Takara) treatment. For RT-PCR, first strand cDNA was synthesized using $2 \mu \mathrm{g}$ total RNA with oligo $\mathrm{d}(\mathrm{T})_{18}$ primer using AMV reverse transcriptase XL (Takara). The PCR reaction of $20 \mu \mathrm{l}$ contained $2.0 \mu \mathrm{l} 10 \times \mathrm{PCR}$ buffer (with $\mathrm{Mg}^{2+}$ ), $0.4 \mu \mathrm{l} 10 \mathrm{mM}$ dNTP mixture, $0.4 \mu \mathrm{l} 10 \mu \mathrm{M}$ each degenerated primers of $C Y C L O I D E A$, a TCP transcriptional factor (forward primer: 5'-AAAGAYCGGCACAGCAARAT-3'; reverse: 5'CCTTTCCCTYGCYCTYGCYCTYGC-3'), $0.2 \mu \mathrm{l}$ Taq polymerase $(2.5 \mathrm{U} / \mu \mathrm{l}$, TIANGEN, China), and $1.0 \mu \mathrm{l} 10$-fold diluted cDNA. The cycling conditions were as follows: predenatutation at $94^{\circ} \mathrm{C}$ for $5 \mathrm{~min}$, then 35 cycles at $94^{\circ} \mathrm{C}$ for $20 \mathrm{~s}$, annealing at $56^{\circ} \mathrm{C}$ for $20 \mathrm{~s}$ and extension at $72^{\circ} \mathrm{C}$ for $30 \mathrm{~s}$, and a final extension for $10 \mathrm{~min}$ at $72{ }^{\circ} \mathrm{C}$. The PCR product was analyzed on $1 \%(\mathrm{w} / \mathrm{v})$ agarose gel electrophoresis.

The 5' RLM-RACE of Tree Peony APETALA1 gene was obtained using the FirstChoice RLM-RACE Kit (Ambion) with the following primer (5'TTGGAGTATTCTAGGGACCAGTT'T-3'), according to the manufacturer's instructions. The opening reading frame (ORF) of the PsAPl was amplified using KOD Plus Polymerase (Toyobo), with the primers AP1-F (5'ATGGGAAGAGGCAGGGTTCA-3') and AP1-R (5'TGCACCAAAGCACCCAAGGT-3').

\section{Results and Discussion}

In perennial woody plants, floral bud initials generate between the end of July and middle of September, and continue to grow till the first chilly days. The differentiation of floral buds is the most critical biological process to anthophyta, which is accompanied with extensive gene expression shift (Horvath 2009). The extraction of high-quality RNA is the first step to perform such kind assay. Floral buds are rich in polysaccharides, polyphenols, and other secondary metabolites, which thus interfere with RNA extraction and downstream applications.

The method based on Trizol has been widely used for RNA isolation from various tissues and species (Kalinowska et al., 2012). We first attempted to use TRNzol reagent to isolate RNA from floral buds of tree peony. However, the TRNzol buffer could not effectively remove bud pigments, making the aqueous phase red after chloroform purification. Moreover, the polyphenols abundant in floral buds were readily oxidized to quinones that could tightly bind proteins and nucleic acids and finally result in brown and insoluble RNA pellets (Muoki et al., 2012). As shown in Fig. 1 (lane 1 and 2), only the smeared $5.8 \mathrm{~S}$ rRNA band could be detected in the well. Thus, the extracted RNA using the TRNzol method is unsuitable for downstream analysis.

RNeasy Plant kit is designed specifically to extract RNA from plant tissues rich in secondary metabolites, such as conifer needles. Indeed, a small amount of RNA was successfully isolated using this kit (Fig.1 lane 3 and 4). However, the buds powder was easy to form a sticky, glue-like gel in Buffer RLT, making the separation of two phases by centrifugation extremely difficult. Moreover, this mixture seriously decreased the selective binding of RNA to the RNeasy membrane. The RNA yield was very low, about $44.5 \mu \mathrm{g} / \mathrm{g}$ fresh weight, and the $\mathrm{A}_{260 / 280}$ ratio was only 1.29 (Table 1 ).

Since the above two guanidine-based RNA extraction protocols could not give satisfactory results, we tried to use a CTAB-based method to isolate RNA from Tree Peony floral buds. The CTAB method has been widely used for RNA isolation from polyphenols and polysaccharides-rich plants, including pine needles (Chang et al., 1993), a variety of tissues and organs of Chinese fir (Wang et al., 2007, 2011), cotton (Zhao et al., 2012), Spurge (Xu et al., 2010), and tea (Muoki et al., 2012). Unexpectedly, it failed to extract high quality RNA from floral buds of tree peony. The isolated RNA appeared degraded, featured as smear in the lane and bright $5.8 \mathrm{~S}$ rRNA band (Fig. 1 lane 5 and 6). The yield was as low as $94.4 \mathrm{\mu g} / \mathrm{g}$ fresh weight, and the purity was also not well (Table 1). This was probably caused by the cross reaction between $\mathrm{LiCl}$ and the complicated secondary metabolites in floral buds, which thus highly impaired RNA precipitation efficiency.

Next, we attempted to use a SDS-based method, which can effectively remove polysaccharides and has been successfully used to isolate RNA from onion epidermis (Zhou et al., 1999) and lily floral organs (Wu et al., 2006). Importantly, a $\mathrm{LiCl}$ precipitation step was used before the phenol/chloroform purification and the isopropanol precipitation, which could minimize gel formation in the homogenate by dissolution of the gel-forming materials (Zhou et al., 1999). It could successfully isolate RNA with high yield $(186.5 \mu \mathrm{g} / \mathrm{g}$ fresh weight), but the $A_{260 / 280}$ ratio was very low (Fig. 1, lane 7 and 8; 

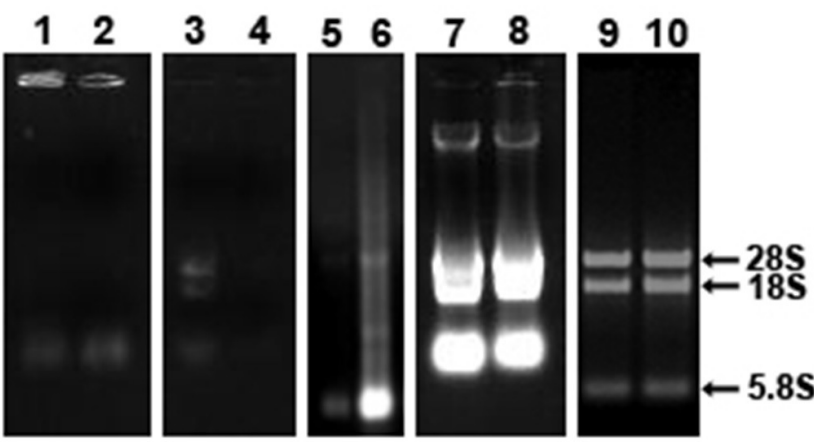

Fig. 1. Agarose gel electrophoresis of total RNA from floral buds of Tree Peony. Lane 1-2: RNA isolated using TRNzol reagent (TIANGEN). Lane 3-4: RNA isolated using RNeasy Plant kit (Qiagen). Lane 5-6: RNA isolated using the CTAB-based method. Lane 7-8: RNA isolated using the conventional SDS protocol. Lane 9-10: RNA isolated using the modified SDS/TRNzol method. All lanes were loaded about $1 \mu \mathrm{g}$ total RNA
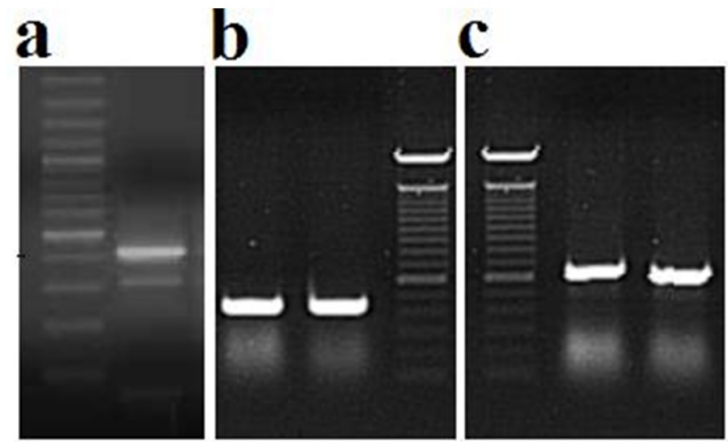

Fig. 3. Downstream application of RNA isolated from floral buds of Tree Peony using the modified SDS/TRNzol method. (a) Homolog fragment of CYCLOIDEA transcriptional factor obtained from Tree peony. (b) 5' RACE product of APETALAI gene. (c) The ORF product of APETALA1. DNA Ladder: $100 \mathrm{bp}$ a

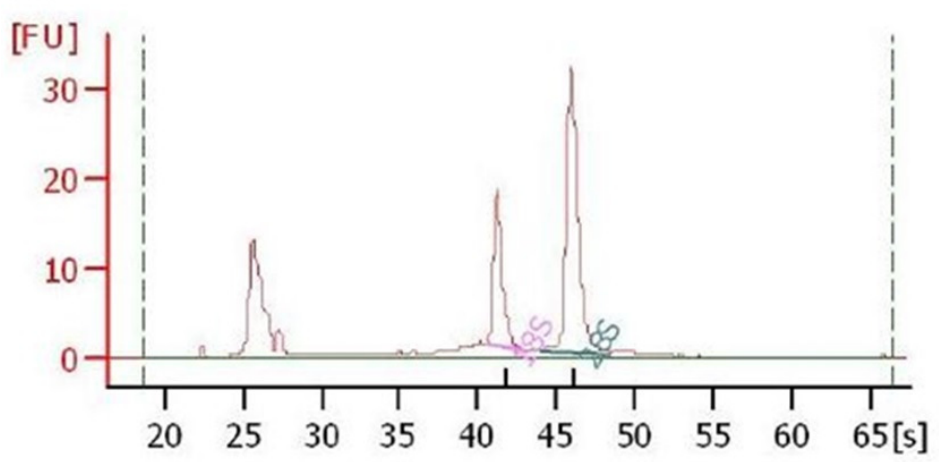

RNA Concentration:

rRNA Ratio [28s / 18s]:

RNA Integrity Number (RIN):
$466 \mathrm{ng} / \mu \mathrm{l}$

2.1

$9.2(B .02 .05)$ b

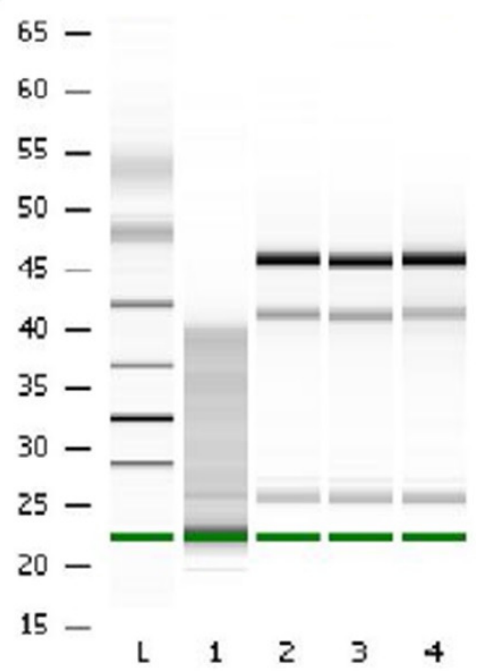

Fig. 2. Analysis of total RNA isolated from floral buds of Tree Peony using the Eukaryote total RNA nano assay on the Agilent 2100 bioanalyzer. (a) Microcapillary electrophoresis of RNA extracted using the modified SDS/TRNzol method present on the right panel with detailed parameters: concentration $466 \mathrm{ng} / \mu \mathrm{l}$, rRNA ratio 2.1, and RNA integrity number 9.2. (b) The corresponding gel-like image generated by the bioanalyzer. L, RNA ladder; 1 : RNA isolated using TRNzol reagent, as a negative control. 2-4: RNA isolated using the modified SDS/TRNzol method

Table 1). There was also considerable amount of genomic DNA contamination in the extracted RNA. Additionally, the entire procedure was time-consuming and labor-intensive.

A recently published SDS/TRNzol RNA extraction protocol was then applied to isolate RNA from floral buds of tree peony. The method is suitable for isolating RNA from samples containing high levels of starch (Wang et al., 2012). Two critical steps were performed before the conventional TRNzol extraction. First, the alkaline condition ( $\mathrm{pH} 9.0)$ in the suspension buffer was feasible to lyse cells and inhibit endogenous ribonuclease. Second, a high concentration of SDS was used to promote cell lysis and to inhibit homogenate solidification by effectively dissolving polysaccharides in samples. In addition, we added an SSTE washing step that could cleanup contaminants co-precipitated with RNA. The result showed that the modified SDS/TRNzol method could effectively isolate high quality RNA from floral buds of tree peony.

Table 1. Yield and purity of total RNA extracted by the five methods from floral buds of tree peony

\begin{tabular}{|c|c|c|c|c|c|}
\hline \multirow[b]{2}{*}{ Method } & \multicolumn{3}{|c|}{ NanoDrop $^{\text {TM }} 1000$} & \multicolumn{2}{|c|}{ Bioanalyzer } \\
\hline & $\mathrm{A}_{260 / 280}$ & $\mathrm{~A}_{260 / 230}$ & $\begin{array}{c}\text { Yield } \\
(\mu \mathrm{g} / \mathrm{g} \text { fresh weight })\end{array}$ & RIN & $\begin{array}{c}\text { rRNA ratio } \\
(28 S / 18 S)\end{array}$ \\
\hline TRNzol & $1.53 \pm 0.15$ & $0.59 \pm 0.10$ & $32.9 \pm 5$ & 2.2 & 0.0 \\
\hline RNeasy & $0.90 \pm 0.05$ & $0.42 \pm 0.08$ & $44.5 \pm 3$ & nd & nd \\
\hline СТAB & $1.58 \pm 0.02$ & $1.47 \pm 0.05$ & $94.4 \pm 5$ & nd & nd \\
\hline SDS & $1.69 \pm 0.05$ & $1.18 \pm 0.03$ & $186.5 \pm 10$ & nd & nd \\
\hline SDS/TRNzol & $1.95 \pm 0.03$ & $2.06 \pm 0.03$ & $165.7 \pm 8$ & 9.2 & 2.1 \\
\hline
\end{tabular}


422

The yield of total RNA obtained by this method was 165.7 $\mu \mathrm{g} / \mathrm{g}$ fresh floral buds (Table 1), which was comparable to that of the conventional SDS method. The ratios of $\mathrm{A}_{260 / 280}$ and $\mathrm{A}_{260 / 230}$ were near to 2.0 and above 2.0 , respectively (Table 1 ). This indicated that the extracted RNA is of high purity without detectable contamination of proteins or other secondary metabolites. Electrophoresis on $1 \%$ agarose gel demonstrated that the total RNA is of good integrity, illustrated by the bright and sharp $28 \mathrm{~S}$ and $18 \mathrm{~S}$ rRNA bands and no sign of degradation (Fig. 1 lane 9 and 10). We further analyzed the extracted RNA on an Agilent 2100 Bioanalyzer. Microcapillary electrophoresis displayed three clearly peaks, corresponding to $28 \mathrm{~S}, 18 \mathrm{~S}$ and $5.8 \mathrm{~S}$, respectively (Fig. 2a). The RNA Integrity Number (RIN) value was 9.2, and the rRNA (28S/18S) ratio was 2.1. The schematic gel-like image also showed that the total RNA isolated from floral buds is of high quality (Fig. 2b).

To confirm that the RNA isolated by the modified SDS/TRNzol protocol is suitable for further molecular assays, we reverse transcribed the prepared RNA into cDNA for RTPCR and RACE analyses. A homolog fragment of the CYCLOIDEA transcriptional factor was obtained from tree peony using the degenerated primers. It was about 450-bp inlength and was validated by DNA sequencing (Fig. 3a). To isolate the full-length cDNA of APETALA1, a clear 400-bp PCR product was obtained by performing 5 ' RACE procedure (Fig 3b). Moreover, the opening reading frame (ORF) of APETALA1 was amplified from the cDNAs reverse transcribed from the RNA extracted by our method (Fig. 3c). Taken together, these results indicated that the RNA isolated by the modified SDS/TRNzol protocol is of high quality and is suitable for further gene expression analysis.

\section{Conclusions}

In summary, we systematically compared five commonly used protocols for RNA isolation, and reported a modified SDS/TRNzol method for isolation RNA from floral buds of tree peony. This protocol is an easy, efficient, and highly reproducible method for RNA isolation from floral buds rich in secondary metabolites, and could be potentially widely applied for other ornamental plants.

\section{Acknowledgements}

This work was supported by Shanghai Municipal Administration of Landscaping and City Appearance (G140305).

\section{References}

Chang S, Puryear J, Cairney JA (1993). A simple and efficient method for isolating RNA from pine trees. Plant Molecular Biology Reporter 11(2):114117.
Cooke JE, Eriksson ME, Junttila O (2012). The dynamic nature of bud dormancy in trees: environmental control and molecular mechanisms. Plant, Cell and Environment 35(10):1707-1728.

Horvath DP (2009). Common mechanisms regulate flowering and dormancy. Plant Science 177(6):523-531.

Kalinowska E, Chodorska M, Paduch-Cichal E, Mroczkowska K (2012). An improved method for RNA isolation from plants using commercial extraction kits. Acta Biochimica Polonica 59(3):391-393.

Mornya PMP, Cheng FY, Li HY (2011). Chronological changes in plant hormone and sugar contents in cv. Ao-Shuang autumn flowering tree peony. Horticultural Science 38(3):104112.

Muoki RC, Paul A, Kumari A, Singh K, Kumar S (2012). An improved protocol for the isolation of RNA from roots of tea (Camellia sinensis (L.) O. Kuntze). Molecular Biotechnology 52(1):82-88.

Wang G, Gao Y, Wang J, Yang L, Song R, Li X, Shi J (2011). Overexpression of two cambium-abundant Chinese fir (Cunninghamia lanceolata) alpha-expansin genes CIEXPAI and CIEXPA2 affect growth and development in transgenic tobacco and increase the amount of cellulose in stem cell walls. Plant Biotechnology Journal9(4):486-502.

Wang G, Gao Y, Yang L, Shi J (2007). Identification and analysis of differentially expressed genes in differentiating xylem of Chinese fir (Cunninghamia lanceolata) by suppression subtractive hybridization. Genome 50(12):1141-1155.

Wang G, Wang G, Zhang X, Wang F, Song R (2012). Isolation of high quality RNA from cereal seeds containing high levels of starch. Phytochemical Analysis 23(2):159-63.

Wister JC (1995). The peonies. Hopkins, MN, American Peony Society 140-173.

Wu X, Xi M, Miao H, Shi J (2006). Comparison and analysis of extracting methods of the total RNA in lily. Molecular Plant Breeding 4(6):871876 (in Chinese).

XuJ, Aileni M, Abbagani S, Zhang P (2010). A reliable and efficient method for total RNA isolation from various members of spurge family (Euphorbiaceae). Phytochemical Analysis 21(5):395-398.

Zhao L, Ding Q, Zeng J, Wang FR, Zhang J, Fan SJ, He XQ (2012). An improved CTAB-ammonium acetate method for total RNA isolation from cotton. Phytochemical Analysis 23(6):647-650.

Zhou J, Pesacreta TC, Brown RC (1999). RNA isolation without gel formation from oligosaccharide-rich onion epidermis. Plant Molecular Biology Reporter 17(4):397-407. 